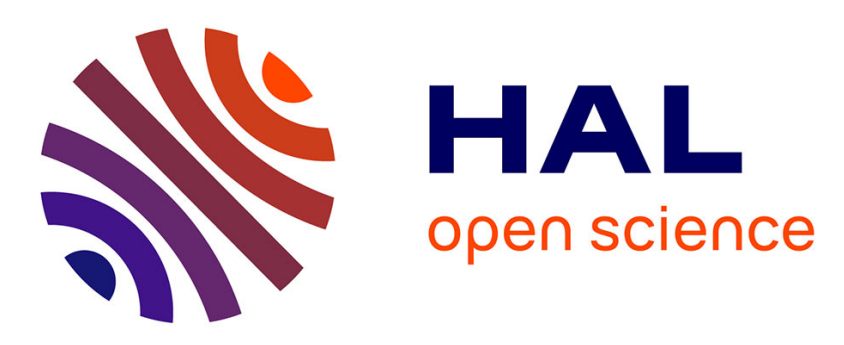

\title{
Multiparametric imaging of adhesive nanodomains at the surface of Candida albicans by atomic force microscopy
}

\author{
Cécile Formosa-Dague, Marion L Schiavone, Anita Boisrame, Mathias L \\ Richard, Raphael E Duval, Etienne Dague
}

\section{To cite this version:}

Cécile Formosa-Dague, Marion L Schiavone, Anita Boisrame, Mathias L Richard, Raphael E Duval, et al. Multiparametric imaging of adhesive nanodomains at the surface of Candida albicans by atomic force microscopy. Nanomedicine: Nanotechnology, Biology and Medicine, 2015, 11 (1), pp.57-65. 10.1016/j.nano.2014.07.008 . hal-01553144

\author{
HAL Id: hal-01553144 \\ https://hal.laas.fr/hal-01553144
}

Submitted on 7 Sep 2017

HAL is a multi-disciplinary open access archive for the deposit and dissemination of scientific research documents, whether they are published or not. The documents may come from teaching and research institutions in France or abroad, or from public or private research centers.
L'archive ouverte pluridisciplinaire HAL, est destinée au dépôt et à la diffusion de documents scientifiques de niveau recherche, publiés ou non, émanant des établissements d'enseignement et de recherche français ou étrangers, des laboratoires publics ou privés. 
1 Multiparametric imaging of adhesive nanodomains at the surface of

\section{Candida albicans by Atomic Force Microscopy}

4 Cécile Formosa, $\mathrm{MS}^{1,2,3,4}$, Marion Schiavone, $\mathrm{MS}^{1,2}$, Anita Boisrame, $\mathrm{PhD}^{5,6}$, Mathias L. Richard,

$7 \quad{ }^{1}$ CNRS, LAAS, 7 avenue du Colonel Roche, F-31400 Toulouse, France

$8 \quad{ }^{2}$ Université de Toulouse ; LAAS, F31400 Toulouse, France

$9 \quad{ }^{3}$ CNRS, UMR 7565, SRSMC, Vandœuvre-lès-Nancy, France

$10{ }^{4}$ Université de Lorraine, UMR 7565, Faculté de Pharmacie, Nancy, France

115 INRA, UMR1319 Micalis, F-78352 Jouy-en-Josas, France

$12{ }^{6}$ AgroParisTech, UMR Micalis, F-78850 Thiverval Grignon, France

$13{ }^{7}$ ABC Platform ${ }^{\circledR}$, Nancy, France

15 Corresponding author: Etienne Dague, LAAS-CNRS, 7 av du Colonel Roche, 31400 Toulouse,

16 France. Phone number: +33 561337841 Mail : edague@laas.fr

18 Abstract word count: 138 words / Manuscript word count: 4451 words / Number of figures: 5 /

19 Number of references: 40

21 This work was supported by an ANR young scientist program (AFMYST project ANR-11-JSV5-

22 001-01 $\left.\mathrm{n}^{\circ} \mathrm{SD} 30024331\right)$ to ED. CF and MS are respectively supported by a grant from

23 "Direction Générale de l'Armement" (DGA) and from Lallemand SAS. 


\section{$25 \underline{\text { Abstract }}$}

26 Candida albicans is an opportunistic pathogen. It adheres to mammalian cells through a variety

27 of adhesins that interact with hosts ligands. The spatial organization of these adhesins on the

28 cellular interface is however poorly understood, mainly because of the lack of an instrument able

29 to track single molecules on single cells. In this context, the Atomic Force Microscope (AFM)

30 makes it possible to analyze the force signature of single proteins on single cells. The present

31 study is dedicated to the mapping of the adhesive properties of C. albicans cells. We observed

32 that the adhesins at the cell surface were organized in nanodomains composed of free or

33 aggregated mannoproteins. This was demonstrated by the use of functionalized AFM tips and

34 synthetic amyloid forming/disrupting peptides. This direct visualization of amyloids

35 nanodomains will help in understanding the virulence factors of $C$. albicans. 


\section{Background}

The yeast Candida albicans has emerged as a major public health problem these last two

40 decades. This opportunistic pathogen causes a wide range of infections from surface infections, to

41 mucosal and blood-stream infections ${ }^{1}$. Whereas mucosal infections are common and occur in

42 healthy organisms, blood-stream infections are observed only in immunocompromised patients

43 and are life-threatening. This type of infections, also known as candidaemia, can develop into

44 disseminated candidiasis when the infection spreads to internal organs, leading to high mortality

45 rates $^{2}$. In order to colonize and subsequently to disseminate in the blood stream C. albicans needs

46 to adhere to different substrates. This first stage of infection ${ }^{3}$ is mediated by adhesins that are

47 found on the surface of the yeast cell wall. Many of these adhesins are mannoproteins, and

48 among them, the adhesin family identified as having a major role in host cell attachment is the

49 Als (Agglutinin-like Sequences) family ${ }^{4}$.

The Als were initially reported as having homologies with the proteins responsible for

51 auto-agglutination in the baker yeast Saccharomyces cerevisiae. Eight Als have been identified,

52 they all are primarily involved in host-pathogen interactions ${ }^{5}$. It was found that there were

53 amyloid-forming sequences in the Als adhesins of Candida albicans ${ }^{6}$. Amyloids are insoluble

54 fibrillar protein aggregates whose core consists in crystalline arrays of identical sequence in many

55 molecules of the amyloid protein ${ }^{7,8}$. Cells expressing the Als proteins can rapidly aggregate, and

56 the aggregation has amyloid-like properties. Like amyloid formation, aggregation ability

57 propagates through the adherent cell population and depends on conformational changes of the

58 Als protein. This transition of the conformational state to an aggregative state of the proteins is

59 characterized by the formation of hydrophobic nanodomains on the entire surface of the cell ${ }^{9}$.

60 A few papers written by Lipke's team were dedicated to the direct visualization of these

61 nanodomains using fluorescent dyes such as thioflavin $\mathrm{T}$ or 8-anilino-1-naphtalene-sulfonic acid 
62 (ANS $)^{6,8,9}$. Another technique that can be used to visualize these nanodomains is Atomic Force

63 Microscopy (AFM). AFM has recently emerged as a valuable tool to study the surface of living

64 cells $^{10}$, and especially pathogenic cells ${ }^{11}$. This technology has been used by Alsteens et al. to

65 image the formation and propagation of nanodomains in living yeast cells ${ }^{12}$ and also to unfold

66 amyloid proteins from the yeasts surface using Single Molecule Force Spectroscopy ${ }^{13-15}$. To this

67 end, the authors functionalized AFM tips with antibodies targeted against the Als protein directly

68 or against an epitope tag present in the Als protein. These studies allowed the authors to localize

69 the adhesive nanodomains caused by the aggregation of Als proteins at the surface of living yeast

70 cells, and to unravel the structure of the Als proteins studied by stretching.

71 In our study, we used AFM as an imaging tool to visualize and localize adhesins

72 nanodomains at the surface of living wild-type Candida albicans cells. Using recent

73 developments in the AFM technology, we have imaged and quantified at the same time the

74 nanomechanical properties, the adhesiveness (force and nature of the interaction), the size and the

75 thickness of the nanodomains ${ }^{16,17}$, at high resolution. The data collected showed that these

76 nanodomains are localized differently at the surface of the cell, depending on the structures

77 featured by the cells (bud scars, buds). We also showed that there were degrees of adhesiveness,

78 depending on whether the amyloid proteins had totally aggregated (hydrophobic nanodomains) or

79 not, and that these degrees of aggregation were directly correlated to the stiffness of the yeast cell

80 wall. Finally, using force measurements and amyloid forming or inhibiting peptides, we showed

81 that Als proteins (probably among others) were participating to these nanodomains.

82

83 Methods

$84 \quad$ Yeasts growth conditions 
85 Candida albicans (from ABC Platform ${ }^{\circledR}$ Bugs Bank, Nancy, France) was stocked at $-80^{\circ} \mathrm{C}$,

86 revivified on Yeast Peptone Dextrose agar (Difco, 242720-500g) and grown in Yeast Peptone

87 Dextrose broth (Difco, 242820-500g) for 20 hours at $30^{\circ} \mathrm{C}$ under static conditions.

\section{Sample preparation for AFM experiments}

90 Yeast cells were concentrated by centrifugation, washed two times in acetate buffer (18 $\mathrm{mM}$

$91 \mathrm{CH}_{3} \mathrm{COONa}, 1 \mathrm{mM} \mathrm{CaCl}, 1 \mathrm{mM} \mathrm{MnCl} 2, \mathrm{pH}=5.2$ ), resuspended in acetate buffer, and

92 immobilized on polydimethylsiloxane (PDMS) stamps prepared as described by Dague et $a l^{18}$.

93 Briefly, freshly oxygen activated microstructured PDMS stamps were covered by a total of 100

$94 \mu \mathrm{L}$ of the solution of cells and allowed to stand for 15 minutes at room temperature. The cells

95 were then deposited into the microstructures of the stamp by convective/capillary assembly.

96 Images were recorded in acetate buffer in Quantitative Imaging ${ }^{\mathrm{TM}}$ mode with MLCT AUWH

97 (Bruker) cantilevers (nominal spring constant of $0.01 \mathrm{~N} / \mathrm{m}$ ). The applied force was kept at $1.5 \mathrm{nN}$

98 for imaging and at $0.5 \mathrm{nN}$ for force spectroscopy experiments. The loading rate for imaging was

99 of $2500000 \mathrm{pN} / \mathrm{s}$ (acquisition frequency of the force curves is of $25 \mathrm{~Hz}$ ) and for force

100 spectroscopy of $75000 \mathrm{pN} / \mathrm{s}$ (acquisition frequency of the force curves is of $1.25 \mathrm{~Hz}$ ). For

101 imaging and force spectroscopy, we used an AFM Nanowizard III (JPK Instruments, Berlin,

102 Germany). The cantilevers spring constants were determined by the thermal noise method ${ }^{19}$. For

103 all the results presented in this study, silicon nitride AFM tips were bare, expect in the case of

104 figure 4g (lower panel), where a functionalized AFM tip has been used.

\section{AFM tips functionnalization}

107 The functionalized tips were produced according to a french patent of the authors described later

108 in sensors and actuators ${ }^{20}$. Briefly, AFM tips were functionalized with dendrimers presenting 
$109 \mathrm{CHO}$ functions able to covalently link with $\mathrm{NH}_{2}$ functions of proteins. These dendritips were then

110 incubated with the lectin Concanavalin A (Sigma, L7647-100MG, 100 $\mathrm{g} / \mathrm{mL}$ ) for 1 hour, before

111 being used for force spectroscopy experiments.

112

\section{Results analysis}

114 All results were analyzed using the Data Processing software from JPK Instruments. The stiffness

115 values measured on cells were determined from the slope of the linear portion of the raw 116 deflections versus piezo displacement curves, according to:

$$
k c e l l=k\left(\frac{s}{1-s}\right)
$$

117 with $s$ the experimentally accessible slope of the compliance region reached for sufficient loading

118 forces. In this model, the experimental setup can be represented by two linear springs, one is the

119 AFM's cantilever, and the other is the cell envelope exhibiting an effective spring constant. It is 120 then possible to calculate the effective spring constant kcell of the cell envelope from the 121 observed slope $s$ of the force curve and the known spring constant $k$ of the cantilever ${ }^{21}$.

\section{$123 \underline{\text { Results }}$}

\section{Candida albicans cells display localized adhesiveness}

125 Thanks to our innovative method to immobilize cells into PDMS stamps ${ }^{18}$, and using

126 Quantitative Imaging ${ }^{\mathrm{TM}}$ mode $^{16}$, we were able to image and quantify the adhesive properties of

127 single $C$. albicans cells at the same time. Figure 1a shows a budding yeast cell; on the

128 corresponding adhesion image (Figure 1b), we can see that only the bud, and not the mother-cell,

129 presents adhesives patches. This original result is surprising as non-budding cells are highly

130 adhesive (see below). This result seems to indicate that the mother-cell cell wall changes during 
131 the budding process. As for the cell in figure 1c, this cell displays two bud scars, a common

132 feature at the surface of yeast cells, which are not adhesive whereas the rest of the cell is. This

133 type of distribution of the adhesion on yeast cells has already been seen using

134 immunofluorescence with antibodies targeted against surface proteins of $C$. albicans. Coleman et

$135 a l$. for example showed that the Als1 protein was expressed all over C. albicans cells, with the

136 exception of bud scars ${ }^{22}$. The comparison of our results to these data suggests then that the

137 adhesions probed by AFM might be due to surface proteins, such as Als1 in the case of the cell

138 presenting bud scars, but perhaps also others adhesins.

\section{C. albicans cell wall adhesins are able to aggregate into nanodomains}

As showed before ${ }^{9,12}$, the proteins expressed at the surface of $C$. albicans cell wall are

142 able to aggregate, and to form nanodomains. However, these nanodomains have not been yet

143 characterized at the nanoscale, nor were imaged at high resolution. In fact, these nanodomains

144 have specific adhesive properties that can be mapped using AFM in the Quantitative Imaging ${ }^{\mathrm{TM}}$

145 mode. High resolution (256 pixels ${ }^{2}$ ) adhesive images are presented in Figure 2. It shows adhesive

146 nanodomains, at the surface of a living wild-type C. albicans cell. On the cell presented in this

147 figure (Figure 2a), the corresponding adhesion image shows very distinct adhesive nanodomains

148 that were probed with bare AFM tips. These nanodomains are homogeneously distributed all over

149 the cell here, which does not present any morphological features such as buds or bud scars. When

150 zooming into small areas on top of the cell (white squares on figure $2 b$ ), we could measure the

151 area of each nanodomain. On this cell and on another one showed in Figure 3a, 60 nanodomains

152 areas were measured; the values obtained plotted on figure $2 \mathrm{e}$ shows that nanodomains have an

153 average area of $0.09 \pm 0.03 \mu \mathrm{m}^{2}$. This corresponds to an average diameter of $170 \mathrm{~nm}$, which

154 confirms the nanoscale of these nanodomains. Some of the nanodomains are also higher than the 
155 rest of the cell wall. When the whole cell is imaged, it is not visible; however, specific analysis of

156 the Figure $3 d$ and the graphic $3 h$ representing the topography of the cell surface revealed

157 nanodomains that had a different height compared to the rest of the cell. The cross-sections taken

158 along the blue line showed the height of a nanodomain of $20 \mathrm{~nm}$. Once again, this confirmed the

159 nanoscale of the nanodomains at the surface of $C$. albicans.

161 Different nanodomains have different nanomechanical properties

162 Adhesion is measured as the rupture force recorded when retracting the tip from the surface,

163 when approaching and pulling with the tip on the cell wall, thus AFM makes it possible to 164 measure nanomechanical properties of living cells. Here we choose to use an analysis based on 165 the Hooke model which considers the coupled cantilever / cell wall as a spring. The stiffness 166 values measured on cells were determined from the slope of the linear portion of the raw 167 deflections versus piezo displacement curves, according to:

$$
k c e l l=k\left(\frac{s}{1-s}\right)
$$

168 with $s$ the experimentally accessible slope of the compliance region reached for sufficient loading

169 forces. Indeed, the most interesting result in this study is the correlation that can be directly made

170 between the adhesiveness of the nanodomain, and its stiffness. Nanodomains on figure $3 \mathrm{e}$

171 (adhesion map) circled in red were found on the stiffness image (figure 3f) circled in black; they

172 correspond to the zones where the stiffness of the cell wall is increased, to $13.4 \pm 0.3 \mathrm{nN} / \mu \mathrm{m}$. As

173 for less adhesive nanodomains, they do not present any difference in stiffness from the rest of the

174 cell, and are $12.4 \pm 0.2 \mathrm{nN} / \mu \mathrm{m}$. The 3D-view of the adhesion, mapped with the stiffness (figure

$1753 \mathrm{~g}$ ) illustrates this clear correlation; the more adhesive the nanodomain is, the stiffer it is. 
Another fascinating point is that for the more adhesive nanodomains, the retract force

177 curves present typical hydrophobic adhesions ${ }^{23-25}$, with adhesions occurring immediately when

178 the tips is retracted from the surface. Force curves from the other, less adhesive, nanodomains

179 presented retract adhesions resembling to proteins unfolding, occurring several nanometers after

180 the tip withdrawal. Therefore it seems that the nanodomains are of 2 different natures. There is a

181 class of nanodomains, hydrophobic, higher and stiff, and another class displaying proteins

182 unfolding properties, as soft as the rest of the cell wall. What is the molecular nature of these 2

183 types of nanodomains, and are they correlated?

185 Understanding the adhesive properties of the 2 nanodomains classes

186 To answer the previous question, we monitored the retract force curves recorded on the 187 nanodomains (Figure 4). We found the same correlation as in figure 3; the force curves recorded 188 on an adhesive nanodomains presented hydrophobic retract adhesions, whereas the force curves

189 recorded on a less adhesive nanodomain presented protein, unfolding like, profiles. In order to 190 determine the nature of these last unfoldings, we probed the surface of $C$. albicans cells with an

191 AFM tip functionalized with Concanavalin A (ConA), a protein that interacts with yeast 192 mannoproteins, such as surface adhesins. The resulting force curves (figure $4 \mathrm{~g}$ ) showed retract 193 adhesions displaying unfoldings of different lengths, but with a similar profile. We also observed 194 condensed spikes with adhesion forces between 0 and $50 \mathrm{pN}$. This value was consistent with 195 specific interactions between ConA and mannoproteins ${ }^{26}$.

196 In a previous study conducted in $2009^{14}$ by Alsteens et al., adhesins (Als5) were unfolded 197 from the surface of live S. cerevisiae cells overexpressing this protein. The retract force curves 198 obtained in this study show high similarity with the ones we obtain here with functionalized AFM 199 tips, with the presence of serin-threonin rich segments (condensed pikes on figure $4 \mathrm{~g}$ ). We can 
therefore, based on this comparison with the data of the literature, conclude that the less adhesive

201 nanodomains at the surface of live $C$. albicans are composed of free adhesins, and maybe of Als

202 proteins. However, since all adhesins (like Als, Hwp1, Eap1, Rbt1 etc) are mannoproteins, we

203 cannot, at this stage, make a statement on which adhesins are unfolded here.

As for the second type of nanodomains, the hydrophobic ones, our hypothesis is that they are composed of the same proteins as the less adhesive ones. In fact, adhesins (like Als) display amyloids sequences located on a domain of the protein called $\mathrm{T}$, that enable them to change their conformation $^{6}$ and to aggregate into amyloid nanodomains. And when this phenomena is started,

208 it propagates to the whole cell ${ }^{9}$. We therefore made the hypothesis that the adhesive nanodomains are in fact amyloid nanodomains, made of Als proteins.

\section{From adhesins to amyloid nanodomains: the role of Als proteins}

To verify this hypothesis, and according to the literature on Als proteins, we synthesized a

213 peptide exhibiting the same sequence as the one of the $T$ domain of the Als $1 / 3 / 5$ proteins. We

214 then put this peptide in the presence of the cells in order to trigger the amyloids formation. We

215 also synthesized the same peptide, but with a mutation on one amino acid (V326N peptide), in

216 order to obtain a peptide that inhibits the formation of the amyloid nanodomains ${ }^{8}$. Since Als 3 is

217 only expressed on the surface of hyphae, we will only be able to generate or destroy the amyloid

218 formation of Als 1 and 5. The results presented in figure 5 showed a cell before and after adding

219 the mutated peptide. We can clearly see on these adhesion images the loss of general adhesion

220 and of two nanodomains at the center of the cell. It seems like the mutated peptide disrupted the

221 amyloids at the surface of the cell. And the other way around, when cells were incubated with the

222 amyloid forming peptide, we could observe the formation of the nanodomains at the surface of

223 the cells, as it is showed on the adhesion images on local areas on top of $C$. albicans cells in 
224 figure 5c, d and e. These results allow us to conclude that the proteins at the origin of the 225 nanodomains are then mannoproteins, more specifically Als1 or 5, or both, that form amyloids.

\section{Discussion}

We show in this study that wild-type live $C$. albicans cells exhibit extraordinary adhesive

229 properties. In the case of budding cells, placed in acetate buffer at $25^{\circ} \mathrm{C}$ for $2 \mathrm{~h}$, we observed that

230 the mother cell is not adhesive and that only the bud presents adhesive nanodomains. On the

231 contrary, we show that non budding cells are covered by adhesive nanodomains, in the same

232 experimental conditions. This illustrates the amazing plasticity of this species ${ }^{27,28}$ able to grow as

233 a commensal or as a pathogen ${ }^{29,30}$, in all the parts of the intestinal track, but also on the vaginal

234 mucosa, as unicellular budding cells or as filamentous hyphae. Moreover its cell wall is

235 permanently remodeled as a reaction to its environment (temperature, $\mathrm{pH}$, dissolved $\mathrm{O}_{2}$, ions,

236 interacting surface/cells/bacteria) what makes it challenging to reproduce the experimental

237 conditions inducing a certain cell wall phenotype. We then demonstrate that the molecules at the

238 origin of these adhesions could aggregate into nanodomains, which can be probed at high

239 resolution using a suited $\mathrm{AFM}$ mode, $\mathrm{QI}^{\mathrm{TM}}$. These nanodomains are different in terms of level of

240 adhesiveness, which is a property directly correlated to their stiffness and to the hydrophobic

241 state or not of the molecule at the origin of these nanodomains. We then went further in the study,

242 using functionalized AFM tips, and were able to determine that the less adhesive nanodomains

243 were formed by mannoproteins that can interact specifically with Concanavalin A. These

244 mannoproteins are able to aggregate to form the adhesive nanodomains because they have

245 amyloid properties as we showed in figure5.

246 Amyloid aggregation is a primitive ${ }^{31}$ and very stable ${ }^{32}$ protein folding and a common 247 structural motif. It is a cross $\beta$-sheet quaternary structure that usually auto-aggregates as fibrils. It 
248 has been, first, associated with neurodegenerative diseases like Alzheimer, Parkinson, or

249 Creutzfeldt-Jakob diseases. However it is more and more unclear if the amyloids lesions are the

250 cause or a consequence of the disease. Amyloid aggregates are now described as functional

251 proteins assembly and can be found from bacteria to humans ${ }^{33}$. In microorganisms, amyloid has

252 been described as a functional coat ${ }^{34}$. It constits in curli (E. coli), chaperons (Streptomyces) or

253 hydrophobins (Aspergillus etc); all of these proteins are implicated in adhesion to the host and in

254 the invasion, infection process. It is now well known that adhesins (and especially Als) of $C$.

255 albicans have amyloid-forming sequences ${ }^{6,35}$ and that these proteins form domains involved in

256 cell aggregation or biofilm formation ${ }^{36}$. Nevertheless the characterization, structure and

257 properties of the amyloids adhesive nanodomains remain unclear.

In this work we measured for the first time the nanoscale size of amyloid domains

259 (average area of $0.09 \mu \mathrm{m}^{2}$ ) at the surface of live C. albicans cells. The domains are of 2 different

260 classes. Some present the characteristic of individual proteins whereas the others are

261 hydrophobic, stiffer than the rest of the cell $(13.4 \pm 0.3 \mathrm{nN} / \mu \mathrm{m}$ compared to $12.4 \pm 0.2 \mathrm{nN} / \mu \mathrm{m})$,

262 and are slightly protruding. It means that there is a state modification from soluble proteins into

263 insoluble proteins, which is a characteristic of amyloid structures. This transformation is

264 dependent on the proteins concentration and can only occur when the protein density exceeds a

265 threshold. The roles of the two classes of domains are probably different. On one hand we could

266 hypothesize that the hydrophobic nanodomains were involved in the cell adhesion to abiotic

267 hydrophobic surfaces or to cell membrane as it is known that membrane binding is an inherent

268 property of amyloid aggregates ${ }^{37,38}$. Amyloid aggregation is also a way to store proteins, in a

269 limited space and to sort them when required. This has been demonstrated for hormones in

270 secretory granules ${ }^{39,40}$. Thus $C$. albicans may store some adhesins for the subsequent invasion

271 phases. On the other hand the protein like domains may be responsible for specific adhesion to 
272 fibronectin and other extra cellular proteins of the matrix. It seems rational that several adhesins,

273 brought together, would be more efficient in a binding process than a single adhesion. This

274 finding has to be added to $C$. albicans plasticity ${ }^{28}$ and participate to explain its remarkable

275 adaptation and pathogenicity.

276 However, there are still many things to explore on the cell wall of $C$. albicans, and future

277 work will be dedicated to exploring the changes appearing on the mother cell during the budding

278 process.

279

280 References

281

282 1. Gow NA, Hube B. Importance of the Candida albicans cell wall during commensalism and 283 infection. Curr Opin Microbiol. 2012;15:406-412.

284 2. Poulain D. Candida albicans, plasticity and pathogenesis. Crit Rev Microbiol. 2013:1-10.

285 3. Naglik JR, Moyes DL, Wächtler B, Hube B. Candida albicans interactions with epithelial 286 cells and mucosal immunity. Microbes Infect. 2011;13:963-976.

287 4. Hoyer LL. The ALS gene family of Candida albicans. Trends Microbiol. 2001;9:176-180.

288 5. Hoyer LL, Green CB, Oh S-H, Zhao X. Discovering the secrets of the Candida albicans 289 agglutinin-like sequence (ALS) gene family - a sticky pursuit. Med Mycol. 2008;46:1-15.

290 6. Ramsook CB, Tan C, Garcia MC, Fung R, Soybelman G, Henry R, et al. Yeast Cell 291 Adhesion Molecules Have Functional Amyloid-Forming Sequences. Eukaryot Cell. $292 \quad 2010 ; 9: 393-404$.

293 7. Sawaya MR, Sambashivan S, Nelson R, Ivanova MI, Sievers SA, Apostol MI, et al. Atomic $294 \quad$ structures of amyloid cross- $\beta$ spines reveal varied steric zippers. Nature. 2007;447:453-457.

295 8. Garcia MC, Lee JT, Ramsook CB, Alsteens D, Dufrêne YF, Lipke PN. A Role for Amyloid 296 in Cell Aggregation and Biofilm Formation. PLoS ONE. 2011;6:e17632.

297 9. Rauceo JM, Gaur NK, Lee K-G, Edwards JE, Klotz SA, Lipke PN. Global Cell Surface 298 Conformational Shift Mediated by a Candida albicans Adhesin. Infect Immun. $299 \quad$ 2004;72:4948-4955. 
10. Müller DJ, Dufrêne YF. Atomic force microscopy: a nanoscopic window on the cell surface. Trends Cell Biol. 2011;21:461-469.

11. Alsteens D, Beaussart A, El-Kirat-Chatel S, Sullan RMA, Dufrêne YF. Atomic Force Microscopy: A New Look at Pathogens. PLoS Pathog. 2013;9:e1003516.

12. Alsteens D, Garcia MC, Lipke PN, Dufrêne YF. Force-induced formation and propagation of adhesion nanodomains in living fungal cells. Proc Natl Acad Sci. 2010;107:20744 20749.

13. Beaussart A, Alsteens D, El-Kirat-Chatel S, Lipke PN, Kucharíková S, Van Dijck P, et al. Single-Molecule Imaging and Functional Analysis of Als Adhesins and Mannans during Candida albicans Morphogenesis. ACS Nano. 2012;6:10950-10964.

14. Alsteens D, Dupres V, Klotz SA, Gaur NK, Lipke PN, Dufrêne YF. Unfolding Individual Als5p Adhesion Proteins on Live Cells. ACS Nano. 2009;3:1677-1682.

15. Alsteens D, Ramsook CB, Lipke PN, Dufrêne YF. Unzipping a Functional Microbial Amyloid. ACS Nano. 2012;6:7703-7711.

16. Chopinet L, Formosa C, Rols MP, Duval RE, Dague E. Imaging living cells surface and quantifying its properties at high resolution using AFM in $\mathrm{QI}^{\mathrm{TM}}$ mode. Micron. 2013;48:2633.

17. Dufrêne YF, Martínez-Martín D, Medalsy I, Alsteens D, Müller DJ. Multiparametric imaging of biological systems by force-distance curve-based AFM. Nat Methods. 2013;10:847-854.

18. Dague E, Jauvert E, Laplatine L, Viallet B, Thibault C, Ressier L. Assembly of live microorganisms on microstructured PDMS stamps by convective/capillary deposition for AFM bio-experiments. Nanotechnology. 2011;22.

19. Hutter JL, Bechhoefer J. Calibration of atomic-force microscope tips. Rev Sci Instrum. 1993;64:1868-1873.

20. Jauvert E, Dague E, Séverac M, Ressier L, Caminade A-M, Majoral J-P, et al. Probing single molecule interactions by AFM using bio-functionalized dendritips. Sens Actuators $B$ Chem. 2012;168:436-441.

21. Arnoldi M, Fritz M, Bäuerlein E, Radmacher M, Sackmann M, Boulbitch A. Bacterial turgor pressure can be leasured by atomic force microscopy. Phys Rev E. 1999;62:1034-1044

22. Coleman DA, Oh S-H, Zhao X, Hoyer LL. Heterogeneous distribution of Candida albicans cell-surface antigens demonstrated with an Als1-specific monoclonal antibody. Microbiology. 2010;156:3645-3659.

23. Dague E, Alsteens D, Latge JP, Verbelen C, Raze D, Baulard AR, et al. Chemical force microscopy of single live cells. Nano Lett. 2007;7:3026-3030. 
24. Alsteens D, Dague E, Rouxhet PG, Baulard AR, Dufrene YF. Direct measurement of hydrophobic forces on cell surfaces using AFM. Langmuir. 2007;23:11977-11979.

25. Dague E, Alsteens D, Latgé J-P, Dufrêne YF. High-Resolution Cell Surface Dynamics of Germinating Aspergillus fumigatus Conidia. Biophys J. 2008;94:656-660.

26. Alsteens D, Dupres V, Evoy KM, Wildling L, Gruber HJ, Dufrêne YF. Structure, cell wall elasticity and polysaccharide properties of living yeast cells, as probed by AFM. Nanotechnology. 2008;19.

27. Odds F. Candida and candidiosis. A review and bibliography. 2nd edition. London: Bailliere Tindall; 1988.

28. Poulain D. Candida albicans , plasticity and pathogenesis. Crit Rev Microbiol. 2013:1-10.

29. Gow NA, Hube B. Importance of the Candida albicans cell wall during commensalism and infection. Curr Opin Microbiol. 2012;15:406-412.

30. Gow NAR, van de Veerdonk FL, Brown AJP, Netea MG. Candida albicans morphogenesis and host defence: discriminating invasion from colonization. Nat Rev Micro. 2012;10:112122.

31. Greenwald J, Riek R. Biology of Amyloid: Structure, Function, and Regulation. Structure. 2010;18:1244-1260.

32. Perczel A, Hudáky P, Pálfi VK. Dead-End Street of Protein Folding: Thermodynamic Rationale of Amyloid Fibril Formation. J Am Chem Soc.;129:14959-14965.

33. Fowler DM, Koulov AV, Balch WE, Kelly JW. Functional amyloid--from bacteria to humans. Trends Biochem Sci. 2007;32:217-224.

34. Gebbink MFBG, Claessen D, Bouma B, Dijkhuizen L, Wösten HAB. Amyloids - a functional coat for microorganisms. Nat Rev Microbiol. 2005;3:333-341.

35. Otoo HN, Lee KG, Qiu W, Lipke PN. Candida albicans Als Adhesins Have Conserved Amyloid-Forming Sequences. Eukaryot Cell. 2008;7:776-782.

36. Garcia MC, Lee JT, Ramsook CB, Alsteens D, Dufrêne YF, Lipke PN. A Role for Amyloid in Cell Aggregation and Biofilm Formation. PLoS ONE. 2011;6:e17632.

37. Sparr E, Engel MFM, Sakharov DV, Sprong M, Jacobs J, de Kruijff B, et al. Islet amyloid polypeptide-induced membrane leakage involves uptake of lipids by forming amyloid fibers. FEBS Lett. 2004;577:117-120.

38. Gellermann GP, Appel TR, Tannert A, Radestock A, Hortschansky P, Schroeckh V, et al. Raft lipids as common components of human extracellular amyloid fibrils. Proc Natl Acad Sci U S A. 2005;102:6297-6302. 
39. Maji SK, Perrin MH, Sawaya MR, Jessberger S, Vadodaria K, Rissman RA, et al. Functional Amyloids As Natural Storage of Peptide Hormones in Pituitary Secretory Granules. Science. 2009;325:328-332.

40. Dannies PS. Concentrating hormones into secretory granules: layers of control. Mol Cell Endocrinol. 2001;177:87-93.

\section{$\underline{\text { Figure Caption }}$}

Figure 1. Localization of the adhesive properties of $\boldsymbol{C}$. albicans cells. (a) Height image (zrange $=1.5 \mu \mathrm{m}$ ) of a budding C. albicans cell in a PDMS stamp, and (b) adhesion image corresponding to the height image. On (a), MC stands for Mother cell, BC stands for Budding cell, and the red dotted line represents the demarcation between the two different cells. (c) Height image (z-range $=3.5 \mu \mathrm{m}$ ) of a single $C$. albicans cell exhibiting two bud scars, and (d) adhesion image corresponding to the height image.

\section{Figure 2. Imaging of the adhesive domains of $C$. albicans cells in acetate buffer, at $25^{\circ} \mathrm{C}$ for} 2 hours. (a) Height image (z-range $=2.5 \mu \mathrm{m}$ ) of a single $C$. albicans cell in a polydimethylsiloxane (PDMS) stamp, and (b) adhesion images corresponding to the height images. (c, d) Adhesion images of small areas on top of the cell, represented by the white squares in b. (e) distribution of the areas values of the domains in $\mathrm{c}$ and $\mathrm{d}$.

Figure 3. Nanomechanics of the adhesive domains of $C$. albicans cells. (a) Height image (zrange $=2.5 \mu \mathrm{m}$ ) of a C. albicans cell in a PDMS stamp, (b) corresponding adhesion image, and (c) corresponding stiffness image. (d) Height image (z-range $=100 \mathrm{~nm}$ ) of a small area on top of the cell, represented by the white square on (a), (e) corresponding adhesion image and (f) corresponding stiffness image. Note that the adhesive nanodomains circled in red on (e) are also 
394 found on the stiffness image (black circles on $\mathrm{f}$ ). ( $\mathrm{g}$ ) is a 3D-image of the adhesion mapped with

395 the stiffness. (h) cross-section taken along the blue line on (d), and (i), distribution of the stiffness

396 values corresponding to the yeast cell wall and the less adhesive domains (blue columns) or to the

397 most adhesive domains (yellow columns).

399 Figure 4. Adhesion force curves of $\boldsymbol{C}$. albicans adhesive domains. (a) Height image (z-range =

$4004.0 \mu \mathrm{m}$ ) of a $C$. albicans cell in a PDMS stamp. (b) Adhesion image of a small area on top of the

401 cell, represented by the white square on (a). (c and d) representative force curves obtained on the

402 zones indicated by the arrows on (c). (e) Height image (z-range $=2.5 \mu \mathrm{m}$ ) of a $C$. albicans cell in

403 a PDMS stamp and (f) corresponding adhesion image recorded with a bare tip. (g) representative

404 force curves obtained in the zone delimited by a white square on (f) with the Con A tip.

405

406 Figure 5. Imaging of the adhesive domains of $C$. albicans cells treated with Als1, 3, 5p 407 amyloid disrupting peptide (V326N peptide) or Als1, 3, 5p amyloid forming peptide (Als 408 peptide). (a) Adhesion image of a single $C$. albicans cell in a PDMS stamp and (b) 409 corresponding adhesion image after adding V326N peptide. (c, $d$ and e) Adhesion images of 410 small areas on top of a $C$. albicans cell after adding the Als peptide. 